\title{
Experimental Validation of a Battery Dynamic Model for EV Applications
}

\author{
Olivier Tremblay ${ }^{1}$, Louis-A. Dessaint \\ Electrical Engineering Department, École de Technologie Supérieure \\ ${ }^{1}$ Email: olivier.tremblay.1@ens.etsmtl.ca
}

\begin{abstract}
This paper presents an improved and easy-to-use battery dynamic model. The charge and the discharge dynamics of the battery model are validated experimentally with four batteries types. An interesting feature of this model is the simplicity to extract the dynamic model parameters from batteries datasheets. Only three points on the manufacturer's discharge curve in steady state are required to obtain the parameters. Finally, the battery model is included in the SimPowerSystems simulation software and used in a detailed simulation of an electric vehicle based on a hybrid fuel cell-battery power source. The results show that the model can accurately represent the dynamic behaviour of the battery.
\end{abstract}

Keywords: Simulation; Battery Model; SimPowerSystems; Fuel Cell Vehicle

\section{Introduction}

The central element of electric vehicles (EV) and of more electric systems in general is the battery. This element stores a great amount of energy to be release when necessary. The battery enables regenerative braking in an EV and allows to supplement a slow dynamic energy source, such as the fuel cell. Benefits are drawn from these features in EVs based on fuel cells such as the Honda FCX Clarity. The battery's management system (BMS) must ensure an efficient management battery's state of charge (SOC). To accomplish this, the designer of the BMS must have a detailed simulation of the EV's traction system including a detailed model of the battery.

There are basically three types of battery models reported in the literature, specifically: experimental, electrochemical and electric circuit-based. Experimental and electrochemical models are not well suited to represent cell dynamics for the purpose of state-ofcharge estimations of battery packs. However, electric circuit-based models can be useful to represent electrical characteristics of batteries. The most simple electric model consists of an ideal voltage source in series with an internal resistance [2]. This model, however, does not take into account the battery SOC. There is another model based on an open circuit voltage in series with a resistance and parallel RC circuits with the so-called Warburg impedance [3]. The identification of all the parameters of this model is based on a rather complicated technique called impedance spectroscopy [4]. Shepherd developed an equation to describe the electrochemical behaviour of a battery directly in terms of terminal voltage, open circuit voltage, internal resistance, discharge current and state-ofcharge [1], and this model is applied for discharge as well as for charge. A modified version of the Shepherd model has been used in [5]. This modification consists on using a polarisation voltage instead of a polarisation resistance in order to remove the algebraic loop problem due to the simulation of electrical systems in Simulink. This model uses only the battery SOC as a state variable to represent the voltage behaviour. This is valid in steady state (constant current) but this model produces false results when the current varies. The main contribution of this paper is to show how the SimPowerSystems battery model was recently improved in order to extend its validity for variable charging or discharging current.

The rest of this paper is organized as follows: In section 2, the mathematical model which varies according to the battery type will be described. Section 3 will present the model's parameters and the procedure to deduct them from the battery manufacturer's discharge curve. Section 4 will present an interesting contribution of this paper as it shows the results of an experimental validation for four types of batteries. Finally, section 5 will present an application of the battery model in a full simulation of the EV traction system based on a fuel cell. 


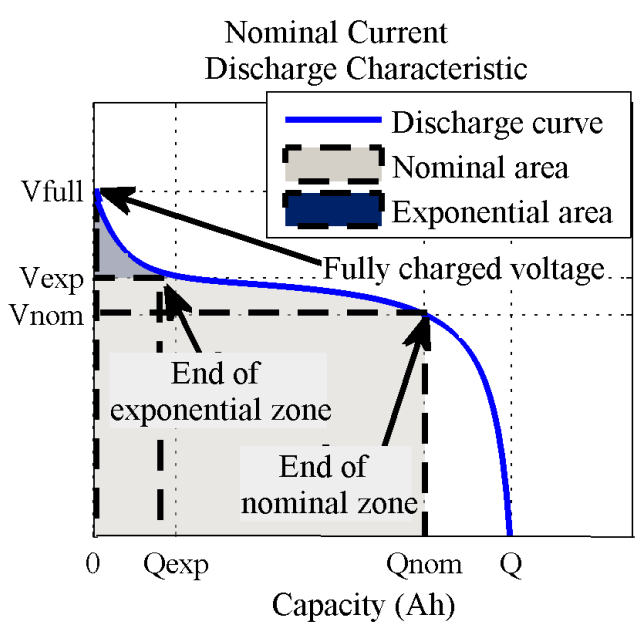

Figure 1: Typical discharge curve

\section{The proposed battery model}

\subsection{The discharge model}

The Fig. 1 shows a typical discharge characteristic, for a Nickel-Metal-Hydrid cell.

The proposed discharge model is similar to the Shepherd model but can represent accurately the voltage dynamics when the current varies and takes into account the open circuit voltage (OCV) as a function of SOC. A term concerning the polarisation voltage is added to better represent the OCV behaviour and the term concerning the polarisation resistance [1] is slightly modified. The battery voltage obtained is given by:

$$
\begin{gathered}
V_{\text {batt }}=E_{0}-\underbrace{K \frac{Q}{Q-i t} \cdot i t}_{\text {Pol. Voltage }}-R \cdot i+ \\
\text { Aexp }(-B \cdot i t)-\underbrace{K \frac{Q}{Q-i t}}_{\text {Pol. Resistance }} \cdot i^{*}
\end{gathered}
$$

where

$$
\begin{aligned}
& V_{\text {batt }}=\text { battery voltage }(V) \\
& E_{0}=\text { battery constant voltage }(V) \\
& K=\text { polarisation constant }(V /(A h)) \text { or polarisation } \\
& \quad \text { resistance }(\Omega) \\
& Q=\text { battery capacity }(A h) \\
& i t=\int i d t=\text { actual battery charge }(A h) \\
& A=\text { exponential zone amplitude }(V) \\
& B=\text { exponential zone time constant inverse }(A h)^{-1} \\
& R=\text { internal resistance }(\Omega) \\
& i=\text { battery current }(A) \\
& i^{*}=\text { filtered current }(A)
\end{aligned}
$$

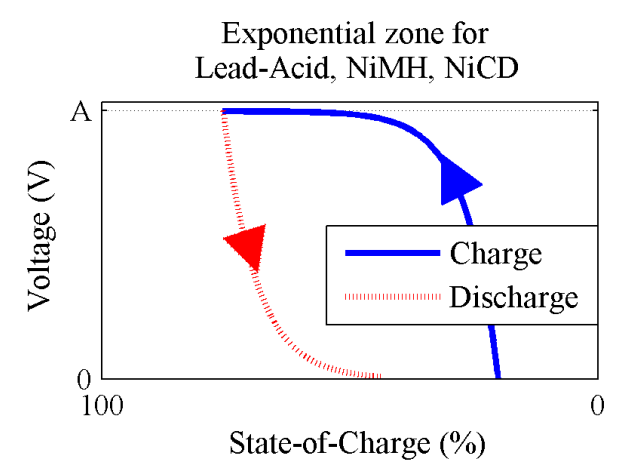

Figure 2: Hysteresis phenomenon

The particularity of this model is the use of a filtered current $\left(i^{*}\right)$ flowing through the polarisation resistance. In fact, experimental results show a voltage slow dynamic behaviour for a current step response. This filtered current solve also the algebraic loop problem due to the simulation of electrical systems in Simulink. Finally, the OCV varies non-linearly with the SOC. This phenomenon is modelled by the polarisation voltage term.

The exponential zone of equation (1) is valid for the Li-Ion battery. For the other batteries (Lead-Acid, $\mathrm{NiMH}$ and NiCD), there is a hysteresis phenomenon between the charge and the discharge, no matter the SOC of the battery [6], [7]. This behaviour occurs only in the exponential area, as shown in Fig. 2.

This phenomenon can be represented by a non-linear dynamic system:

$$
\dot{E x p}(t)=B \cdot|i(t)| \cdot(-\operatorname{Exp}(t)+A \cdot u(t))
$$

where

$$
\begin{aligned}
& \operatorname{Exp}(t)=\text { exponential zone voltage }(V) \\
& i(t)=\text { battery current }(A) \\
& u(t)=\text { charge or discharge mode }
\end{aligned}
$$

The exponential voltage depends on its initial value $\operatorname{Exp}\left(t_{0}\right)$ and the charge $(\mathrm{u}(\mathrm{t})=1)$ or discharge $(\mathrm{u}(\mathrm{t})=$ 0 ) mode. Fig. 3 shows the complete discharge model system.

\subsection{The charge model}

The charge behaviour, particularly the end of the charge (EOC) characteristic, is different and depends on the battery type.

\subsubsection{Lead-Acid and Li-Ion batteries}

The Lead-Acid and Li-Ion batteries have the same EOC characteristics, because the voltage increases rapidly when the battery reaches the full charge. This phenomenon is modelled by the polarisation resistance term. In the charge mode, the polarisation resistance increases until the battery is almost fully charged (it $=0$ ). Above this point, the polarisation resistance increases abruptly. 


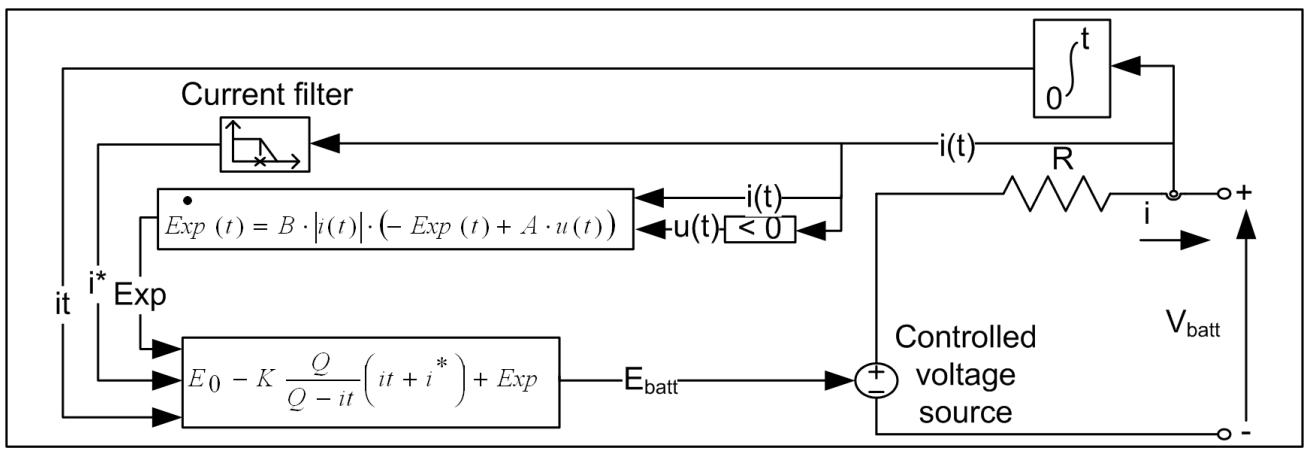

Figure 3: Discharge battery model

Instead of the polarisation resistance of the discharge model (equation (1)), the polarisation resistance is now given by:

$$
\text { Pol. Resistance }=K \frac{Q}{i t}
$$

Theoretically, when it $=0$ (fully charged), the polarisation resistance is infinite. This is not exactly the case in practice. Indeed, experimental results have shown that the contribution of the polarisation resistance is shifted by about $10 \%$ of the capacity of the battery. Equation (3) can be re-written to:

$$
\text { Pol. Resistance }=K \frac{Q}{i t-0.1 \cdot Q}
$$

Similar to the discharge model, the exponential voltage for the Li-Ion battery is the $A \cdot \exp (-B \cdot i t)$ term and for the Lead-Acid, the voltage is given by equation (2).

\subsubsection{NiMH and NiCd batteries}

These two types of batteries have a particular behaviour at EOC. Indeed, after the battery has reached the full charge voltage, the voltage decreases slowly, depending on the current amplitude. This phenomenon is very important to model because a battery charger monitors the $\Delta V$ value to stop the charge.

This behaviour is represented by modifying the charge polarisation resistance. When the battery is fully charged $(i t=0)$, the voltage starts to drop. The charger continues to overcharge the battery $(i t<0)$ and the voltage decreases. This phenomenon can be represented by decreasing the polarisation resistance when the battery is overcharged by using the absolute value of the charge (it):

$$
\text { Pol. Resistance }=K \frac{Q}{|i t|-0.1 \cdot Q}
$$

Similar to the discharge model, the exponential voltage for these batteries is given by equation (2).

\subsubsection{The charge model overview}

The complete charge model is similar to the one in Fig. 3 . Only the $E_{b a t t}$ calculation differs, depending on the battery type:
- Lead-Acid : $E_{\text {batt }}=E_{0}-K \frac{Q}{i t-0.1 \cdot Q} \cdot i^{*}-$ $K \frac{Q}{Q-i t} \cdot i t+\operatorname{Exp}(t)$

- Li-Ion : $E_{\text {batt }}=E_{0}-K \frac{Q}{i t-0.1 \cdot Q} \cdot i^{*}-K \frac{Q}{Q-i t}$. $i t+A \exp (-B \cdot i t)$

- $\mathrm{NiMH}$ and $\mathrm{NiCd}: E_{\text {batt }}=E_{0}-K \frac{Q}{|i t|-0.1 \cdot Q}$. $i^{*}-K \frac{Q}{Q-i t} \cdot i t+\operatorname{Exp}(t)$

\subsection{Model summary}

\subsubsection{Lead-Acid}

- Discharge : $V_{b a t t}=E_{0}-R \cdot i-K \frac{Q}{Q-i t} \cdot(i t+$ $\left.i^{*}\right)+\operatorname{Exp}(t)$

- Charge : $V_{\text {batt }}=E_{0}-R \cdot i-K \frac{Q}{i t-0.1 \cdot Q} \cdot i^{*}-$ $K \frac{Q}{Q-i t} \cdot i t+\operatorname{Exp}(t)$

\subsubsection{Li-Ion}

- Discharge : $V_{b a t t}=E_{0}-R \cdot i-K \frac{Q}{Q-i t} \cdot(i t+$ $\left.i^{*}\right)+A \exp (-B \cdot i t)$

- Charge : $V_{\text {batt }}=E_{0}-R \cdot i-K \frac{Q}{i t-0.1 \cdot Q} \cdot i^{*}-$ $K \frac{Q}{Q-i t} \cdot i t+A \exp (-B \cdot i t)$

\subsubsection{NiMH and NiCd}

- Discharge : $V_{b a t t}=E_{0}-R \cdot i-K \frac{Q}{Q-i t} \cdot(i t+$ $\left.i^{*}\right)+\operatorname{Exp}(t)$

- Charge : $V_{b a t t}=E_{0}-R \cdot i-K \frac{Q}{|i t|-0.1 \cdot Q} \cdot i^{*}-$ $K \frac{Q}{Q-i t} \cdot i t+\operatorname{Exp}(t)$

The proposed model is based on specific assumptions and has limitations: 


\begin{tabular}{||c||c|c|c|c||}
\hline \hline Type & $\begin{array}{c}\text { Lead- } \\
\text { Acid } \\
\text { Parameters }\end{array}$ & NiCd & Li-Ion & NiMH \\
\hline$E_{0}(V)$ & 12.4659 & 1.2705 & 3.366 & 1.2816 \\
\hline $\mathrm{R}(\Omega)$ & 0.04 & 0.003 & 0.01 & 0.002 \\
\hline $\mathrm{K}(\Omega$ or $V /(A h))$ & 0.047 & 0.0037 & 0.0076 & 0.0014 \\
\hline $\mathrm{A}(\mathrm{V})$ & 0.83 & 0.127 & 0.26422 & 0.111 \\
\hline $\mathrm{B}(A h)^{-1}$ & 125 & 4.98 & 26.5487 & 2.3077 \\
\hline \hline
\end{tabular}

Table 1: Battery parameters

\subsubsection{Model assumptions}

- The internal resistance is supposed constant during the charge and discharge cycles and does not vary with the amplitude of the current.

- The model's parameters are deduced from the discharge characteristics and assumed to be the same for charging.

- The capacity of the battery does not change with the amplitude of the current (No Peukert effect).

- The temperature does not affect the model's behaviour.

- The Self-Discharge of the battery is not represented.

- The battery has no memory effect.

\subsubsection{Model limitations}

- The minimum No-Load battery voltage is $0 \mathrm{~V}$ and the maximum battery voltage $2 * E_{0}$.

- The minimum capacity of the battery is $0 \mathrm{Ah}$ and the maximum capacity Q. Therefore, the maximum SOC cannot be greater than $100 \%$ if the battery is overcharged.

\section{Extracting the parameters}

An important feature of the proposed model is the simplicity with which the dynamic model parameters are extracted. In fact, it is not necessary to take experimental measures on the battery in order to extract the parameters. Only three points on the manufacturer's discharge curve, in steady state, are required to obtain the parameters. Battery manufacturers provide datasheet which includes a "Typical Discharge Characteristics" curve (Fig. 1) where it is possible to extract the fully charged voltage (Vfull), the end of the exponential zone (Qexp, Vexp), the end of the nominal zone (Qnom, Vnom) (when the voltage starts to drops abruptly) and the maximum capacity (Q). Also, the internal resistance $(\mathrm{R})$ is generally given.

With these three points, it is possible to solve, using equation 1, the following set of equations (equations 6 , 7 and 8). Note that the manufacturer curve is obtained at constant current (generally equal to $0.2 \mathrm{C}$ ).

For the fully charged voltage, the extracted charge is 0 $(i t=0)$ and the filtered current $\left(i^{*}\right)$ is 0 because the current step has just started:

$$
V_{f u l l}=E_{0}-R \cdot i+A
$$

For the end of the exponential zone, the factor B can be approximated to 3/Qexp since the energy of the exponential term is almost $0(5 \%)$ after 3 time constants. The filtered current $\left(i^{*}\right)$ is equal to " $\mathrm{i}$ " because the current is in steady state:

$$
\begin{array}{r}
V_{\exp }=E_{0}-K \frac{Q}{Q-Q \exp } \cdot(Q \exp +i)- \\
R \cdot i+A \exp \left(\frac{-3}{Q \exp } \cdot Q \exp \right)
\end{array}
$$

The nominal zone voltage is given by:

$$
\begin{array}{r}
V_{\text {nom }}=E_{0}-K \frac{Q}{Q-Q n o m} \cdot(\text { Qnom }+i)- \\
R \cdot i+A \exp \left(\frac{-3}{Q \exp } \cdot \text { Qnom }\right)
\end{array}
$$

Finally, the time constant of the filtered current $\left(i^{*}\right)$ is not given by the manufacturer datasheet. Only experimental test can provide this information. However, experimental data have shown a time constant of about 30 secs for the four batteries types.

This general approach can be applied to other battery types to obtain the model parameters. Obviously, these parameters are approximate and the level of accuracy of the model depends on the precision of the points extracted from the discharge curve.

The above approach has been used to extract parameters for Lead-Acid, Nickel-Cadmium, Nickel-MetalHydride and Lithium-Ion batteries. The model parameters found for common battery cells are presented in Table 1 .

\section{The model validation}

The proposed model is first validated at steady state in order to reproduce the manufacturers "Typical Discharge Characteristics" curve. Since most of them do not provide the battery dynamic performance, experimental tests are performed on the battery to demonstrate the validity of the model. 
$\mathrm{E} 0=1.2816, \mathrm{R}=0.002$ $\mathrm{K}=0.0014043, \mathrm{~A}=0.11104, \mathrm{~B}=2.3077$

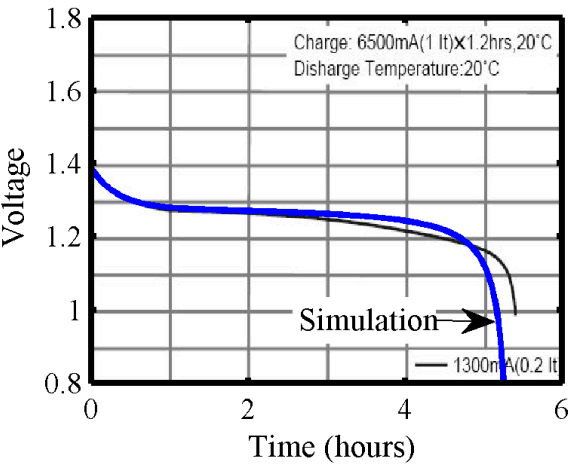

$\mathrm{E} 0=1.2816, \mathrm{R}=0.002$, $\mathrm{K}=0.0014043, \mathrm{~A}=0.11104, \mathrm{~B}=2.3077$

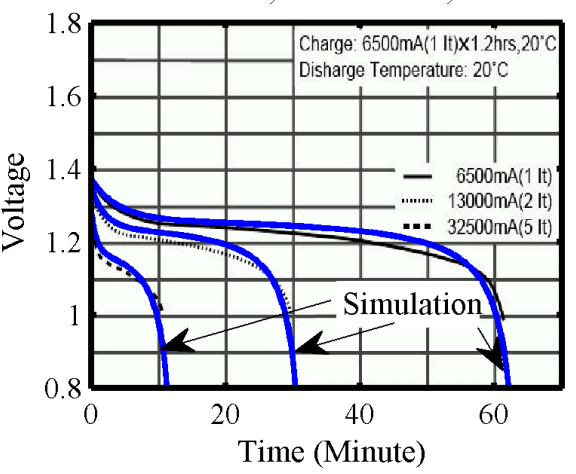

Figure 4: Simulation and datasheet results

\subsection{Steady state validation}

A model of a $6.5 \mathrm{Ah}, 1.2 \mathrm{~V}$, NiMH battery (HHR650D from panasonic $)^{1}$ is obtained using its datasheet:

- Internal resistance $[\mathrm{R}]=0.002 \Omega$

- Discharge current $[\mathrm{i}]=1.3 \mathrm{~A}$

- Maximum capacity [Q] = 7 Ah $(5.38 \mathrm{~h} \times 1.3 \mathrm{~A})$

- Fully charged voltage $[$ Vfull $]=1.39 \mathrm{~V}$

- End of the exponential zone [Qexp,Vexp] $=[1.3$ Ah, $1.28 \mathrm{~V}]$

- Nominal zone [Qnom,Vnom] = [6.25 Ah, 1.18 V]

Fig. 4 shows the simulation results superimposed on the datasheet curve. The first graph shows the voltage vs time for a $0.2 \mathrm{C}$ current and the second graph shows the voltage for $1 \mathrm{C}, 2 \mathrm{C}$ and $5 \mathrm{C}$ currents. The blue solid line represents the simulation results. It is observed that the simulated curves match very well the real curves during almost $90 \%$ of the discharge, no matter the discharge current amplitude.

\footnotetext{
${ }^{1}$ The datasheet can be found at http //www.panasonic.com/industrial/battery /oem/chem/nicmet
}

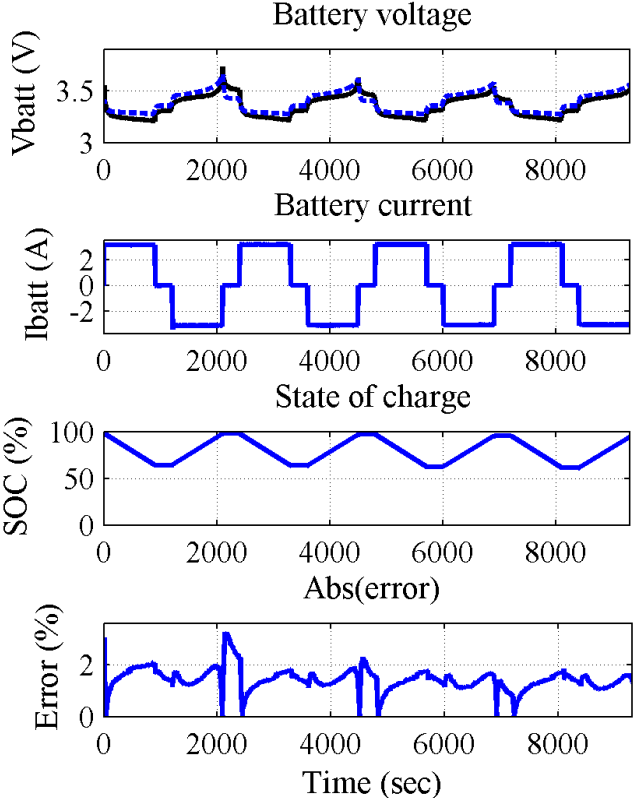

Figure 9: Dynamic charge-discharge of a 2.3Ah, 3.3V Li-Ion battery

\subsection{Validation of dynamic behaviour}

An interesting feature of this paper is the validation of the battery's dynamic behaviour with respect to current variation and the battery's SOC. The validation has been done using chart recorder and a current controlled load. A contact resistance has been added to the simulation model to represent the voltage drop caused by the battery terminals.

Figs. 5, 6, 7 and 8 show the simulation results superimposed to the experimental results for the four batteries types. The parameters of these batteries are those found in Table 1. The first graph shows the experimental battery voltage (black solid line) and the simulated battery voltage (blue dotted line). The second graph represents the battery current. The third graph shows the estimated battery SOC. Finally, the absolute error (in percent) between the measured and simulated voltage is shown in the fourth graph.

It can be noted that the error between the simulated voltage and the real voltage is within $\pm 5 \%$ for SOC between $100 \%$ and $20 \%$ during the charge and the discharge mode. When the SOC decreases below 20 $\%$, the precision of the simulation model is around $\pm 10 \%$. This is quite acceptable because it is not recommended to fully discharge a battery. However, the Lead-Acid battery model has a validity domain between $100 \%$ and $30 \%$ (SOC) because the Peukert effect is not taken into account.

A critical test for the battery model is to switch between the charge and the discharge modes in order to verify the model's continuity. Fig. 9 shows four discharge-charge cycles for the Li-Ion battery. Results show that the model has a precision within $\pm 3 \%$.

Another important point is the validation of the hysteresis effect for the NiMH battery. Fig. 10 shows one charge-discharge cycle for a $2 \mathrm{Ah}, 1.2 \mathrm{~V}$ NiMH battery. 


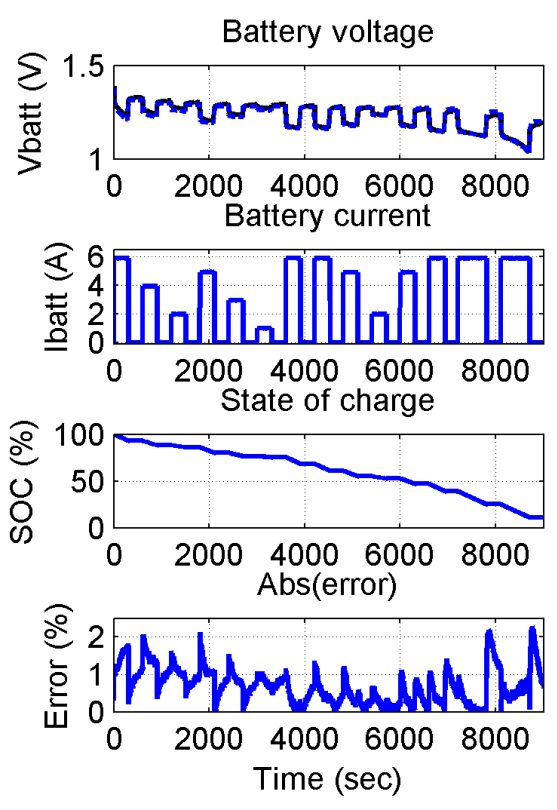

(a) Discharge
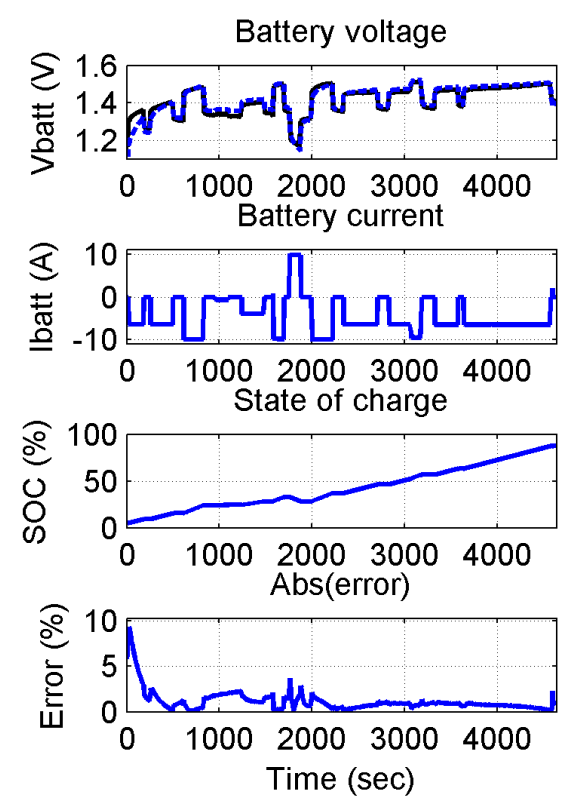

(b) Charge

Figure 5: Dynamic discharge and charge of a 6.5Ah, 1.2V NiMH battery

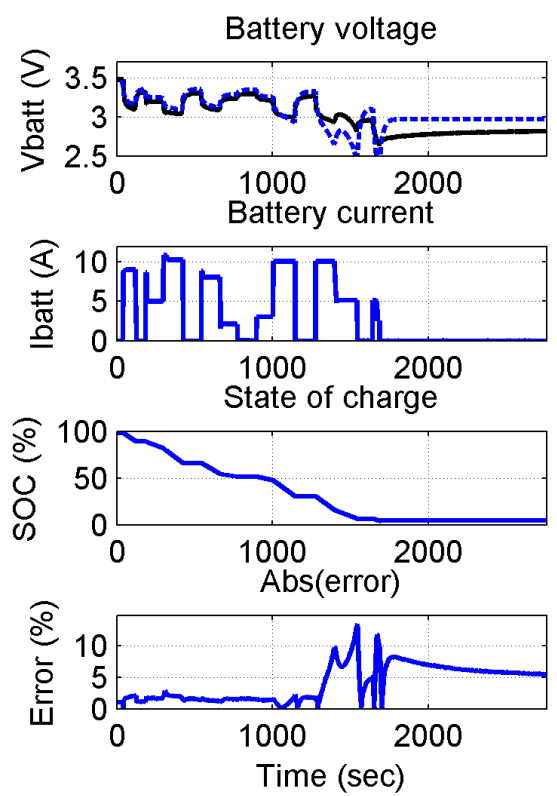

(a) Discharge
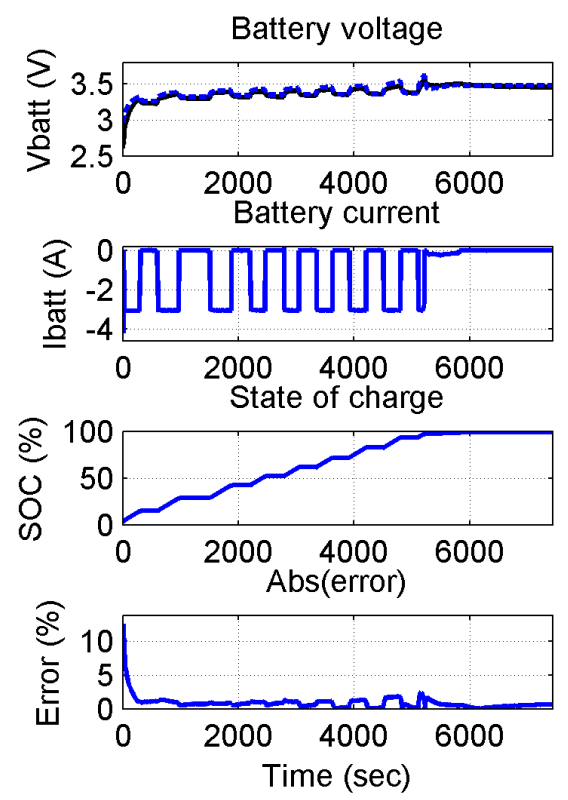

(b) Charge

Figure 6: Dynamic discharge and charge of a 2.3Ah, 3.3V Li-Ion battery 


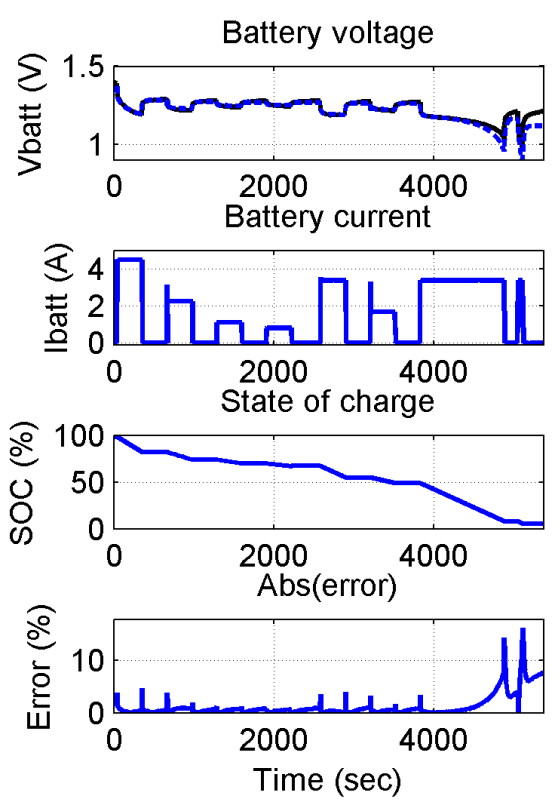

(a) Discharge
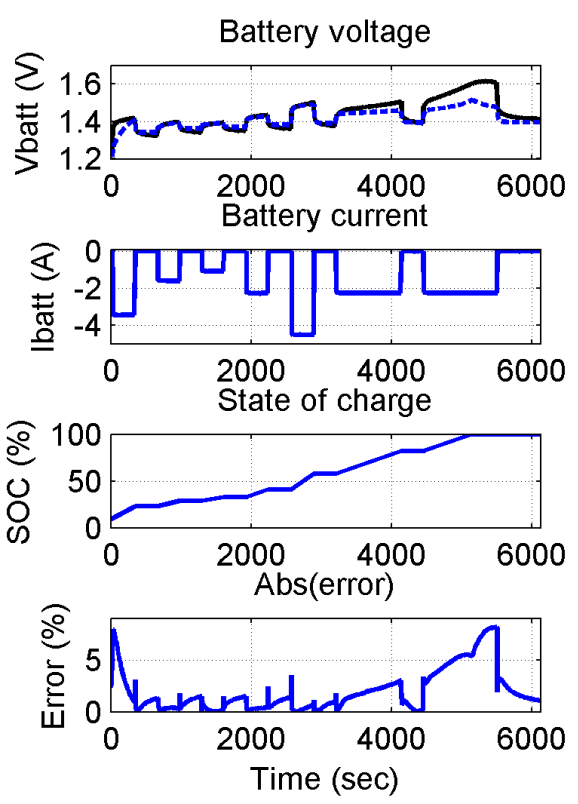

(b) Charge

Figure 7: Dynamic discharge and charge of a 2.3Ah, 1.2 V NiCd battery
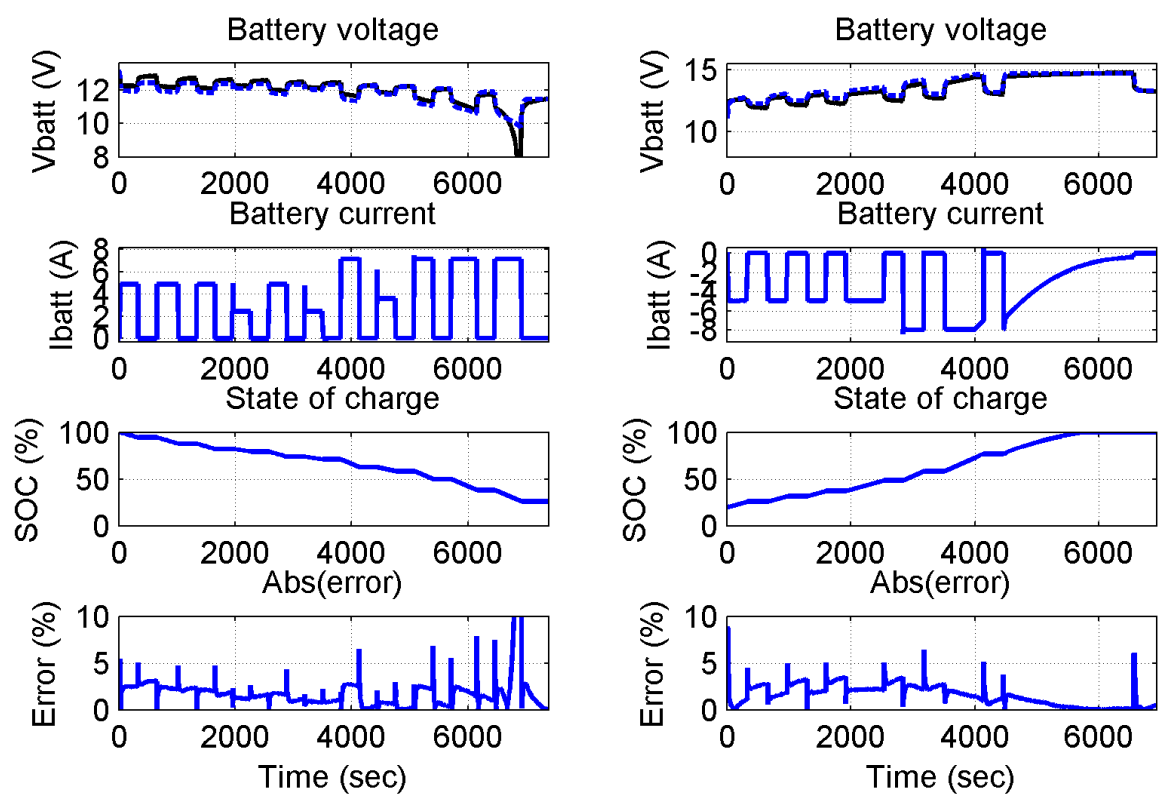

(a) Discharge

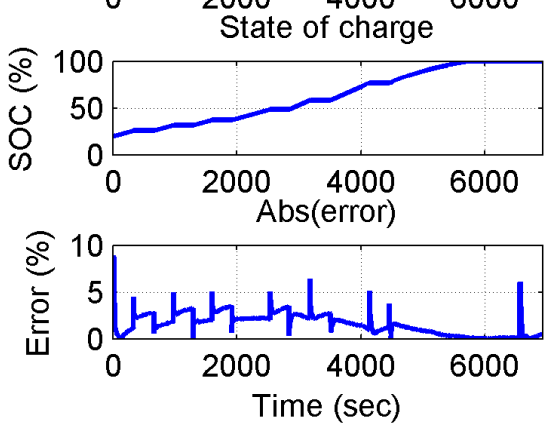

(b) Charge

Figure 8: Dynamic discharge and charge of a 7.2Ah, 12V Lead-Acid battery 


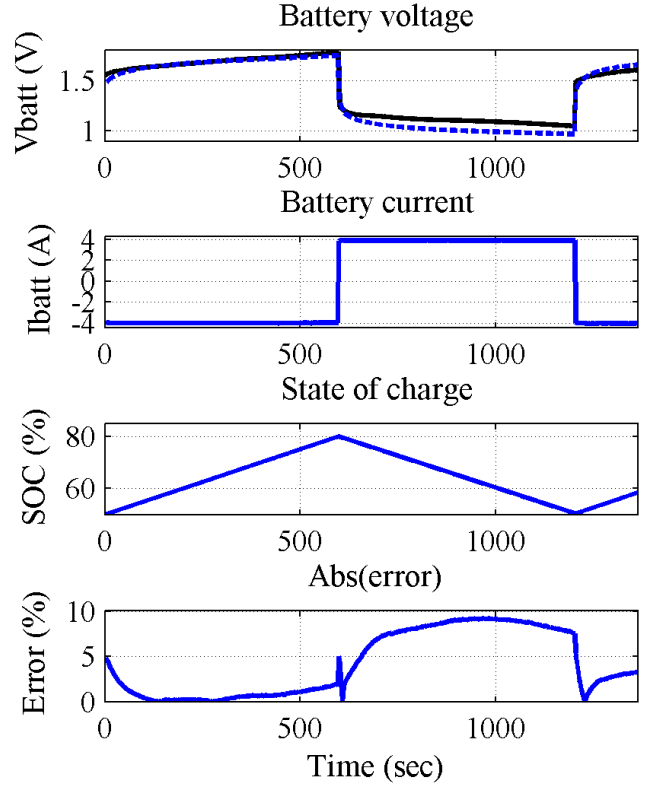

Figure 10: Dynamic charge-discharge of a $2.0 \mathrm{Ah}, 1.2 \mathrm{~V}$ NiMH battery

It can be noted that at the beginning of the simulation (when the charge current of $4 \mathrm{~A}$ is applied), the measured voltage is $1.543 \mathrm{~V}$ and the simulated voltage is $1.471 \mathrm{~V}$. The corresponding error is $4.7 \%$. During the charge period, the error is very low. When the mode changes from the charge to discharge (at $\mathrm{t}=600 \mathrm{secs}$ ), a maximum error of $5 \%$ is noted and this error increases to $9 \%$ in the discharge zone. An important point to note occurs at $t=1200$ secs, where the current becomes negative (charge current). At this time the measured voltage is $1.476 \mathrm{~V}$ and the simulated voltage is $1.396 \mathrm{~V}$, for a corresponding error of $5 \%$. The difference between the voltage at $\mathrm{t}=0 \mathrm{sec}$ and $\mathrm{t}=1200 \mathrm{secs}$ represents the hysteresis phenomenon $(0.067 \mathrm{~V}$ for the experimental results and $0.075 \mathrm{~V}$ for the simulated results). From these results, it can be stated that the hysteresis effect is well represented by the simulation model.

This experimental validation has shown that even if the model parameters are extracted from a steady state curve, it is possible to simulate accurately (error within $\pm 5 \%)$ the dynamic behaviour of the battery for the charge and the discharge processes. The validity domain of the model is included between $100 \%$ and 20 $\%$ of SOC for the NiMH, NiCd and Li-Ion batteries and between $100 \%$ and $30 \%$ for the Lead-Acid battery because the Peukert effect is not modelled. Also, the model behaviour when the current changes suddenly from charge to discharge is coherent with the experimental results. Finally, the model represents well the hysteresis phenomenon for the NiMH battery (the model represents also the effect for the NiCd battery and the small effect appearing with the Lead-Acid battery).

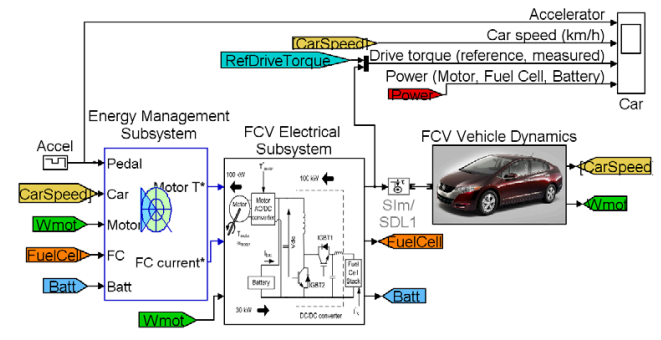

Figure 11: Fuel Cell Vehicle simulation model

\section{Application to a Fuel Cell Elec- tric Vehicle}

The new model is now integrated in the MatlabSimulink SimPowerSystems R2009a library. A userfriendly interface allows the user to enter standardized parameters, and then the model's parameters are calculated automatically according to a similar method to that presented in section 3. The user can then visualize the discharge curve obtained with the parameters and compare it with that of the manufacturer. There are four sets of preset parameters making it possible to represent the behaviour of the batteries determined in Table 1. Of course if desired, it is possible to refine the parameters for a particular battery behaviour.

The model is used in a detailed multi-domain simulation of a EV traction system based on a fuel cell (Fig. 11). The multi-domain simulation allows for the design and fine tuning of the vehicle's energy management system in order to accurately share the electrical power between the two sources of energy and the permanent magnet synchronous motor. The MatlabSimulink blockset series allows to model, in an unique simulation environment, the electrical and mechanical systems and the various control systems. The fuel cell vehicle (FCV) is based on a recent topology, such as the Honda FCX Clarity 2008. The simulation model is composed of three main modules:

- The FCV Electrical Subsystem (Fig. 12) contains a 100 kW, 288 Vdc Interior Permanent Magnet Synchronous Motor (IPMSM) with the associated drive, achieving a maximum motor speed of $12500 \mathrm{rpm}$. The drive is torque regulated and the reference $\left(T_{\text {motor }}^{*}\right)$ comes from the energy management system. The electrical power comes mainly from a $100 \mathrm{~kW}$ Proton Exchange Membrane Fuel Cell (PEMFC). The reference current $\left(I_{F C}^{*}\right)$ is used by the fuel cell system to feed the stack in Hydrogen and Oxygen. Also, this reference current is used by the DC/DC converter (used to interface the fuel cell voltage to the DC bus voltage) to regulate the current fed to the DC bus. During power transients, the fuel cell stack cannot meet the required power due to its large time constant. Therefore, a Li-Ion battery (288 Vdc, $13.9 \mathrm{Ah}, 75 \mathrm{~kW}$ Max) is used to assist the fuel cell and to restore the vehicle braking's energy. Also, the battery is used to re-accelerate the vehicle when the energy is available.

- The Energy Management Subsystem (Fig. 13) represents the key part in this simulation. In fact, 


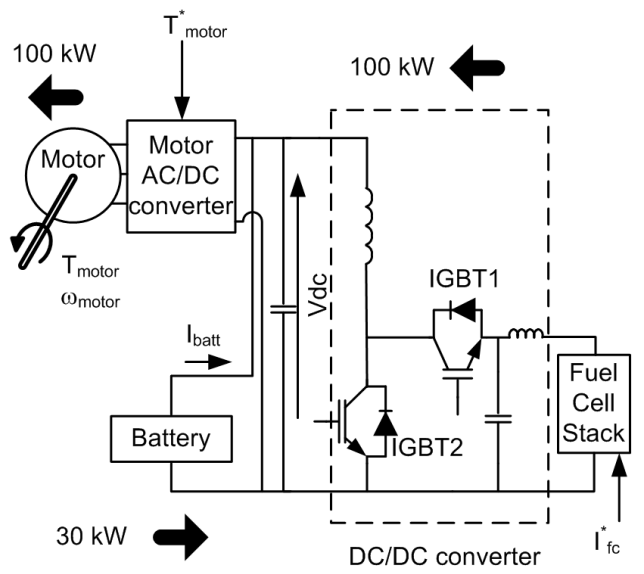

Figure 12: Fuel Cell Vehicle electrical system

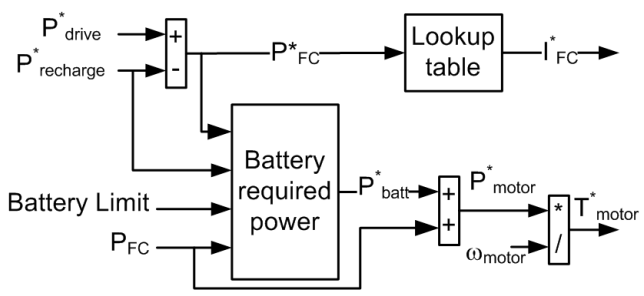

Figure 13: Energy Management System

it determines the required torque of the electrical motor, and the required current of the fuel cell, according to the maximum battery power and the battery SOC. The required vehicle power depends on the pedal position, which varies between -100 $\%$ (full brake) and $100 \%$ (full acceleration). This subsystem contains also a battery management system which ensure that the battery SOC is always between $40 \%$ and $80 \%$.

- The FCV Vehicle Dynamics models, with the SimDriveline blockset, all the mechanical components: reduction gear, differential, tires dynamics and vehicle dynamics.

More particularly, the section concerning the EMS, shown in Fig. 13, is studied. The EMS ensures that the required motor power never exceed the available power. Depending on the pedal position and the vehicle speed, the required drive power $\left(P_{\text {drive }}^{*}\right)$ is calculated. The required fuel cell power $\left(P_{F C}^{*}\right)$ is obtained by subtracting the battery recharge power $\left(P_{\text {recharge }}^{*}\right)$ to $P_{\text {drive }}^{*}$. A lookup table, based on the polarisation curve, is used to calculate the required fuel cell current. As the fuel cell response time is large, the required fuel cell power cannot be obtained instantaneously. The required motor power $\left(P_{\text {motor }}^{*}\right)$ must be limited by the total available power (measured fuel cell power and battery required power) in order to prevent bus voltage collapse. The battery required power $\left(P_{b a t t}^{*}\right)$ is obtained by subtracting the required fuel cell power $P_{F C}^{*}$, to the measured fuel cell power $\left(P_{F C}\right)$. If
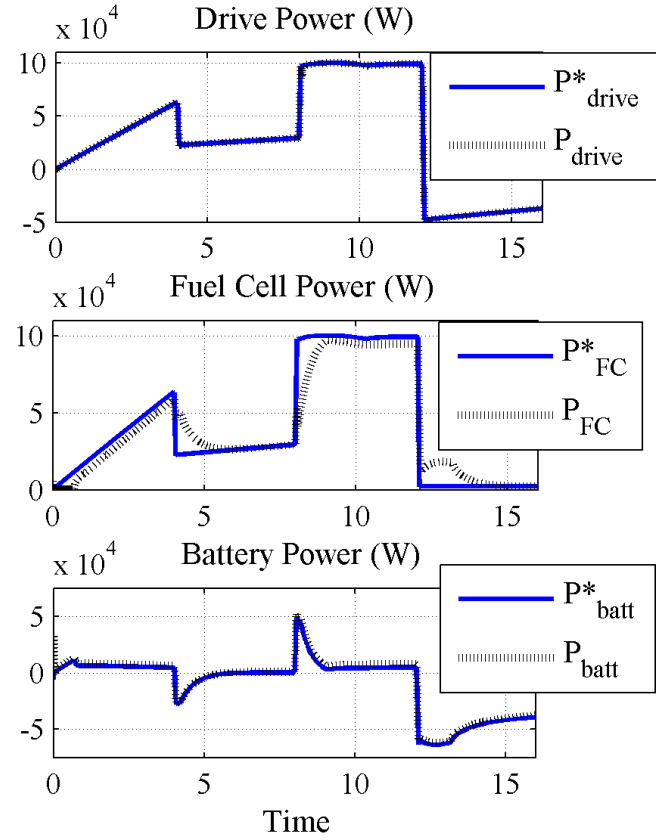

Figure 14: Energy Management System results

required, (depending on the battery SOC and the maximum power) the battery required power is limited. The FCV is simulated during $16 \mathrm{~s}$ and covers four different operation modes: acceleration, cruising, fast acceleration and deceleration. Fig. 14 shows the simulation results:

- At $\mathrm{t}=0 \mathrm{~s}$, the FCV is stopped and the driver pushes the accelerator pedal to $70 \%$. Since the fuel cell cannot start as quickly as required, the battery provides the motor power until the fuel cell starts.

- At $t=0.7 \mathrm{~s}$, the fuel cell begins to provide power but is not able to reach the reference power due to its large time constant. Therefore the battery continues to provide electrical power to the motor.

- At $\mathrm{t}=4 \mathrm{~s}$, the accelerator pedal is released to 25 $\%$. The fuel cell cannot decrease its power instantaneously; therefore the battery absorbs excess of the fuel cell power in order to maintain the required power.

- At $t=6 \mathrm{~s}$, the fuel cell power is equal to the reference power. The battery is no more needed.

- At $\mathrm{t}=8 \mathrm{~s}$, the accelerator pedal is pushed to 85 $\%$. The battery helps the fuel cell by providing an extra power of $50 \mathrm{~kW}$.

- At $\mathrm{t}=9 \mathrm{~s}$, the fuel cell power reaches nearly the reference power of $100 \mathrm{~kW}$. The battery power is progressively reduced to $5 \mathrm{~kW}$.

- At $\mathrm{t}=12 \mathrm{~s}$, the accelerator pedal is set to $-25 \%$, corresponding to a regenerative power of $50 \mathrm{~kW}$. The motor acts as a generator driven by the vehicles wheels. The kinetic energy of the FCV is 
transformed into electrical energy which is stored in the battery. For this pedal position, the battery absorbs the regenerative power and the residual fuel cell power.

- At $\mathrm{t}=15 \mathrm{~s}$, the fuel cell power is about $2 \mathrm{~kW}$ (the minimum power).

Dynamic simulation is one of the first steps in the design of systems such as the FCV. The improvement of the EMS as well as the dimensioning of the components can be obtained when the simulation is done with great exactitude. For example, so as not to exceed the maximum power of the battery, it is possible to directly control the electric motor in order to limit its current. These current peaks can be determined with precision through dynamic simulation.

Simulation using the battery model thus makes it possible to analyse very complex phenomena. In this case, the battery's model parameters are not exactly the same as those of the Honda FCX Clarity battery but it is nevertheless possible to study, with good precision, phenomena caused by the battery. Moreover, this model helps to develop the EMS, which controls all the converters as well as the fuel cell, in order not to exceed the maximum available power. Finally, it is possible to control the charge and the discharge of the battery with precision. This model is thus the central point of the EV's components since all the other systems depend on the battery behaviour.

Although little technical information is available on the Honda FCX Clarity ${ }^{2}$, it has been possible to validate the simulation results using known variables such as the $0-100 \mathrm{~km} / \mathrm{h}$ acceleration, the maximum speed and the hydrogen consumption:

- Fuel consumption of 63.82 miles/kg-H2

- The car makes $0-100 \mathrm{~km} / \mathrm{h}$ in $9 \mathrm{~s}$

- The maximum car speed when the accelerator is $100 \%$ is $165 \mathrm{~km} / \mathrm{h}$ )

\section{Conclusion}

In conclusion, this paper demonstrates that the new SimPowerSystems battery model allows for an adequate representation of a battery's real behaviour based on only three points on the battery manufacturer's discharge curve. It has been demonstrated that even if the points are extracted from a constant-current discharge curve, the dynamic behaviour obtained in simulation is close to the experimental behaviour. Finally, the integration of the new battery model in a multi-domain simulation of an EV based on a fuel cell enables to design and adequately adjust the energy management system as well as the battery's management system. The obtained results are coherent with reality and the vehicle's total energy consumption concords with the public information available on the Honda FCX Clarity.

${ }^{2}$ From the Honda FCX Clarity Press Kit at http://www.hondanews.com, the values are 68 miles/ kg-H2, $0-100 \mathrm{~km} / \mathrm{h}$ in $9.2 \mathrm{~s}$ and $160 \mathrm{~km} / \mathrm{h}$ respectively.

\section{References}

[1] Shepherd, C. M., Design of Primary and Secondary Cells - Part 2. An equation describing battery discharge, Journal of Electrochemical Society, Volume 112, July 1965, pp 657-664.

[2] Durr, Matthias; Cruden, Andrew; Gair, Sinclair; McDonald, J.R, Dynamic model of a lead acid battery for use in a domestic fuel cell system, Journal of Power Sources, Volume 161, no 2, Oct 27, 2006, pp. 14001411.

[3] Kuhn, E.; Forgez, C.; Lagonotte, P.; Friedrich, G., Modelling Ni-MH battery using Cauer and Foster structures, Journal of Power Sources, v 158, no 2 SPEC. ISS., Aug 25, 2006, pp. 1490-1497.

[4] Mauracher, P.; Karden, E., Dynamic modelling of lead/acid batteries using impedance spectroscopy for parameter identification, Journal of Power Sources, v 67, no 1-2, July/August, 1997, pp. 69-84.

[5] Tremblay, O.; Dessaint, L.-A.; Dekkiche, A.-I., A Generic Battery Model for the Dynamic Simulation of Hybrid Electric Vehicles, Vehicle Power and Propulsion Conference, 2007. VPPC 2007. IEEE , pp. 284-289, 912 Sept. 2007.

[6] Rynkiewicz, R., Discharge and charge modeling of lead acid batteries, Applied Power Electronics Conference and Exposition, 1999. APEC '99. Fourteenth Annual, vol.2, no., pp.707-710 vol.2, 14-18 Mar 1999

[7] Feng Xuyun,; Sun Zechang,, A battery model including hysteresis for State-of-Charge estimation in Ni-MH battery, Vehicle Power and Propulsion Conference, 2008. VPPC '08. IEEE, vol., no., pp.1-5, 3-5 Sept. 2008

\section{Authors}

Olivier Tremblay received the B.Ing. and M.Ing. degrees from the École de Technologie Supérieure, Montréal, Qc, Canada in 2004 and 2006, respectively, all in electrical engineering. He is currently a research associate at the École de Technologie Supérieure, Montréal. He is in charge of developing new simulation models and solvers in the SimPowerSystems (SPS). He integrated in SPS the models of the electric battery and the fuel cell and he is author of two important demos of SPS: the multi-domain simulations of the power trains of an HEV and of an electric car based on a fuel cell.

Louis-A. Dessaint received the B.Ing., M.Sc.A., and Ph.D. degrees from the École Polytechnique de Montréal, QC, Canada, in 1978, 1980, and 1985, respectively, all in electrical engineering. He is currently a Professor of electrical engineering at the École de Technologie Supérieure, Montréal. From 1992 to 2001, he was the Director of the Groupe de recherche en électronique de puissance et commande industrielle (GREPCI), a research group on power electronics and digital control. Since 2002, he has been the TransÉnergie (Hydro-Québec) Chair on Power Systems Simulation and Control. He is one of the authors of the SimPowerSystems simulation software of MathWorks. 